\title{
DONDE SE ENMIENDA UN ERROR DE LAS BIBLIOGRAFIAS MANUELMACHADIANAS
}

Los raros estudiosos que nos interesamos por la obra de Manuel Machado venimos aludiendo a un libro de su "prehistoria poética" titulado Etcétera, que decimos fue publicado por él, en colaboración con Enrique Paradas, el año 1895; 1ibro del que, en verdad, ninguno sabemos casi nada.

La existencia de esa obra juvenil fue, según mis noticias, absolutamente ignorada hasta que M. Pérez Ferrero la mencionó, primeramente en un artículo periodístico muy poco conocido y luego en su Vida de Antonio Machado y Manuel $^{1}$, sin dar más datos sobre ella que los de que había sido publicada en colaboración con Paradas y en Barcelona.

A. Carballo Picazo, en su edición de $\mathrm{Alma}_{\mathrm{y}} \mathrm{Apolo}^{2}$, hizo referencia más detenida a ese librito: "Etcétera, en colaboración con Enrique Paradas. Barcelona. A. López Robert. 1895."3

Al año siguiente de la publicación del trabajo de Carballo apareció el de G. Brotherston Manuel Machado. A Revaluation ${ }^{4}$, que en la p. 12 cita Etcétera, aunque fechándolo en 1896, y en la 140 "Etcétera (con Enrique Paradas). Bar-

1 El artículo se titula "Paradas y «La Caricatura»", Arriba, 19 feb. 1947, p. 1. El libro lo publicó Rialp en Madrid, 1947. Cf. p. 71.

2 Alma. Apolo, Alcalá, Madrid, [1967], p. 125.

3 No lo conocen ni J. Romo Arregui, "Manuel Machado: bibliografía", Cuadernos de Literatura Contemporánea, 2, 1942, p. 79-81, ni A. Ruiz Cabriada, Bio-bibliografía

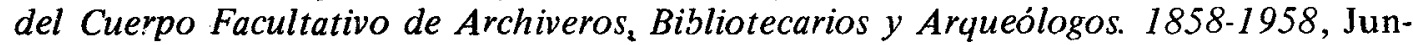
ta Técnica de Archivos, Bibliotecas y Museos, Madid, 1958, p. 565-567.

4 University Press, Cambridge, 1968. 


\section{MIGUEL D'ORS}

celona, López Robert, 1895. 126 pp. The only copy I have seen had one poem by Manuel Machado in it and this was on the last page. Since the copy was in bad condition and lacked an index, other poems by Machado may well have lost.", agrega Brotherston.

J. L. Cano, en su Antologia poética de $\mathbf{M a n u e l}^{5}$, repite, con alguna variante de puntuación, lo dicho por Carballo. En cambio, E. Miró parece haber preferido informarse en Brotherston, pues en la bibliografia de su Antologia manuelmachadiana ${ }^{6}$ escribe: "Etcétera. (En colaboración con Enrique Paradas.) Barcelona, López Robert, 1895. (Volumen inencontrable.)" Sigue también a Carballo J.B. Vega, que en su "Bibliografía de Manuel Machado"7 cita "Etcétera. En colaboración con Enrique Paradas. Barcelona, A. López Robert, 1895”.

Aunque G. Gayton no incluye una bibliografía en su libro sobre Manuel Machado y los poetas simbolistas franceses", alude en el texto, también, a "Etcétera. (1895), colección de la cual sólo queda un ejemplar mutilado en la Biblioteca Machado" "dato que supone un cierto avance con respecto a la información de Brotherston.

La Bibliografia machadiana (Bibliografia para un centenario) confeccionada por la Biblioteca Nacional" menciona asimismo "Etcétera, en colaboración con Enrique Paradas. Barcelona, A. López Robert, 1895, 126 p.”, aunque, dado que ese libro no figura en los catálogos de aquélla, hay que suponer que la información es una sintesis de la de Carballo y la de Brotherston ${ }^{11}$.

Así las cosas, en el caos de la Biblioteca Machado de la Institución "Fernán González" de la Diputación Provincial de Burgos, y con la paciente ayuda de Alicia Yordán Oppenheimer, no he encontrado Etcétera, o-mejor dicho-sí lo he encontrado, pero con otro título: $\&$. Que muy posiblemente haya sido una manifestación más del personalísimo gusto de Manuel Machado en materia de títulos (gusto al que espero dedicar en breve un estudio pormenorizado) ${ }^{\mathbf{1 2}}$. La portada del volumen reza así: 'Paradas-Machado/\&/VERSOS/Barcelona/A. López Robert-impresor/CONDE DEL ASALTO, 63/1895".

10 Servicio de Publicaciones del Ministerio de Educación y Ciencia, Madrid, 1976, p. 36.

11 Iste no dice "A. López Robert", como Carballo, sino "López Robert".

12 In cl primer libro de Machado, Tristes y alegres, publicado -también en colaboración con Paradas - en 1894, hay composiciones que se titulan $; . . . !, * * *$ y ...?; y en Cadencias de cadencias, última obra de Manuel (ya que Horario apareció póstumamente y por lo tanto no pudo ser plenamente supervisado por el poeta), una denominada 14 y otria $\Omega$. 


\section{ERROR DE LAS BIOGRAFIAS MANUELMACHADIANAS}

Es verdaderamente difícil entender cómo ha podido llegar a tradición un error de tal magnitud, mantenido, incluso, por Carballo, Brotherston y G. Gayton, que estuvieron en la biblioteca de Burgos y tuvieron el librito en las manos (a juzgar por los detalles concretos que ofrecen sobre él); pero el hecho ahí está, por inexplicable que sea.

Veamos el ejemplar burgalés: hasta la p. 120 (inclusive) contiene composiciones de Paradas. La 121 es una portadilla que dice: "Manuel Machado". La 122 es blanca. La 123, otra portadilla con el título de una sección: Bocetos. La 124 es blanca también. Las 125 y 126 están ocupadas por un poema en tres décimas, titúlado Ruinas y dedicado "Al Sr. D. Pedro G. Maristany", cuyo texto es:

\footnotetext{
"Resto de antiguos hogares caidas de su grandeza, se alzan entre la maleza de un castillo los sillares. ... Llora el viento sus pesares de las torres al huir, y él oyéndolo gemir, es, á la hiedra abrazado ... algo así como el pasado deteniendo al porvenir.
}

¡Cuántos años han huido desde que pasó la vida por su piedra ennegrecida y su puente demolido! $\mathrm{Si}$, allá, un recuerdo perdido cruza, como una saeta, rozando la silueta de la torre... solo está en la nota que se vá de la lira de un poeta.

En su carrera anhelante el Mundo de ti se olvida, y... adelante va la vida, siempre gritando: adelante. ¡Adiós, recuerdo gigante de aquel pasado glorioso!. . . Vuela el tiempo presuroso, ...y, entre escombros y maleza, hará caer tu grandeza dentro de tu mismo foso!"13 


\section{MIGUEL D'ORS}

Con esto se termina la obra en ese ejemplar.

Sería muy extraño que la aportación de Machado al libro consistiera sólo en 6 páginas, frente a las 114 de Paradas -máxime a la vista de Tristes y alegres, obra paralela a la que considero aquí-, muy extraño que consistiera en un poema ya publicado en aquel libro del año anterior y muy extraño también que para ese único poema se hubiera hecho necesaria una sección con portadilla propia. Por todo ello creo, como Gillian Gayton, que la parte de Machado no se acaba realmente ahí.

Dos caminos se ofrecen ahora a los investigadores: o bien dar una batida por la espesura de la Institución "Fernán González" de Burgos en busca de las páginas desprendidas (que probablemente ya no estén -o no hayan estado nuncaallí), o bien empezar de nuevo a explorar las bibliotecas, pero ahora no persiguiendo en sus catálogos Etcétera sino \& ( ¿y cómo se ordena alfabéticamente un título así?).

Miguel d'Ors Universidad de Granada, otoño de 1979

13 La pieza había aparecido ya, con variantes, en La Caricatura, 58, 27 ago. 1893, s. p.; en La Ilustración Española y Americana, XXXIV, 15 set. 1894, p. 163; y en Tristes y alegres, Imprerita y litografía La Catalana, Madrid, 1894, s. p. 